\title{
A randomized trial of topical anesthesia comparing lidocaine versus lidocaine plus xylometazoline for unsedated transnasal upper gastrointestinal endoscopy
}

Justin Cheung MD FRCPC ${ }^{1}$, Karen J Goodman PhD¹, Robert Bailey MD², Richard N Fedorak MD¹, John Morse MD³, Mario Millan $\mathrm{MD}^{4}$, Tom Guzowski MD³, Sander Veldhuyzen van Zanten MD PhD';

for the CANHelP working group

\begin{abstract}
J Cheung, KJ Goodman, R Bailey, et al; for the CANHelP working group. A randomized trial of topical anesthesia comparing lidocaine versus lidocaine plus xylometazoline for unsedated transnasal upper gastrointestinal endoscopy. Can J Gastroenterol 2010;24(5):317-321.
\end{abstract}

BACKGROUND: The optimal topical anesthesia regimen for unsedated transnasal endoscopy is unknown. The addition of a nasal decongestant, such as xylometazoline (X), to a topical anesthestic may improve patient comfort.

OBJECTIVE: To determine the effectiveness of lidocaine (L) versus $L$ plus $\mathrm{X}$ (LX) for anesthesia in unsedated transnasal endoscopy.

METHODS: Consecutive participants of the Aklavik Helicobacter pylori project were prospectively randomly assigned to receive LX or L for unsedated transnasal $4.9 \mathrm{~mm}$ ultrathin endoscopy. The primary outcome was overall procedure discomfort on a validated 10-point visual analogue scale $(1=$ no discomfort, $10=$ severe discomfort $)$. Secondary outcomes included pain, endoscope insertion difficulty, gagging, adverse events and encounter times. Results were presented as mean \pm SD, difference in mean, $95 \% \mathrm{CI}$.

RESULTS: A total of 181 patients were randomly assigned to receive LX $(n=94)$ and L $(n=87)$. Baseline characteristics between the two groups were similar (mean age 40 years, $59 \%$ women). Overall, patient procedural discomfort with $\mathrm{LX}$ and $\mathrm{L}$ were $4.2 \pm 2.4$ versus $3.9 \pm 2.1$, respectively $(0.29 ; 95 \% \mathrm{CI}-0.39$ to 0.96$)$. Transnasal insertion difficulty was significantly lower with LX than with $\mathrm{L}(2.4 \pm 2.1$ versus $3.2 \pm 2.8$, respectively $[-0.80 ; 95 \% \mathrm{CI}-1.54$ to -0.06$])$. Compared with L, the use of LX was associated with significantly less time needed to apply anesthesia $(2.4 \pm 1.8 \mathrm{~min}$ versus $3.5 \pm 2.2 \mathrm{~min}$, respectively $[-1.10 ; 95 \% \mathrm{CI}-1.71 \mathrm{~min}$ to $-0.50 \mathrm{~min}])$ and less time for insertion $(3.2 \pm 1.8 \mathrm{~min}$ versus $3.9 \pm 2.2 \mathrm{~min}$, respectively [ $-0.70 \mathrm{~min}$; $95 \% \mathrm{CI}-1.30 \mathrm{~min}$ to $-0.10 \mathrm{~min}])$. Epistaxis was rare but occurred less frequently with LX (1.1\%) than with L (4.6\%) ( $\mathrm{P}=0.19)$.

CONCLUSIONS: LX did not improve patient comfort for transnasal endoscopy compared with L alone. However, LX was associated with less difficulty with endoscope transnasal insertion and reduced insertion time. Further studies on the optimal regimen and dosing of anesthesia are required.

Key Words: Topical anesthesia; Transnasal endoscopy; Ultrathin
Un essai aléatoire d'une anesthésie topique comparant la lidocaïne à une association de lidocaïne et de xylométazoline pour l'endoscopie gastroduodénale transnasale sans sédation

HISTORIQUE : On ne sait pas quelle est l'anesthésie topique optimale pour l'endoscopie transnasale sans sédation. L'ajout d'un décongestionnant nasal, tel que la xylométazoline $(\mathrm{X})$, à un anesthésique topique pourrait améliorer le confort du patient.

OBJECTIF : Déterminer l'efficacité de la lidocaïne (L) par rapport à la L associée à la $\mathrm{X}(\mathrm{LX})$ comme anesthésiant en cas d'endoscopie transnasale sans sédation.

MÉTHODOLOGIE : Les participants consécutifs du projet d'Helicobacter pylori Aklavik ont été répartis de manière prospective et aléatoire pour recevoir de la LX ou de la $\mathrm{L}$ afin de subir une endoscopie transnasale ultramince de 4,9 $\mathrm{mm}$ sans sédation. L'issue primaire était l'inconfort pour l'ensemble de l'intervention selon une échelle analogique visuelle de 10 points $(1=$ pas d'inconfort, $10=$ inconfort marqué $)$. Les issues secondaires incluaient la douleur, la difficulté d'insertion de l'endoscope, une réaction nauséeuse, des réactions indésirables et la durée de l'intervention. Les chercheurs ont présenté les résultats sous forme de moyenne \pm ÉT, de différence par rapport à la moyenne, et de $95 \%$ IC.

RÉSULTATS : Au total, 181 patients ont été répartis de manière aléatoire pour recevoir de la LX $(\mathrm{n}=94)$ et de la $\mathrm{L}(\mathrm{n}=87)$. Les caractéristiques de départ entre les deux groupes étaient similaires (âge moyen de 40 ans, 59 \% de femmes). Dans l'ensemble, l'inconfort de l'intervention chez les patients ayant reçu la LX et la $\mathrm{L}$ était de $4,2 \pm 2,4$ par rapport à $3,9 \pm 2,1$, respectivement $(0,29 ; 95 \%$ IC $-0,39$ à 0,96$)$. La difficulté d'insertion transnasale était beaucoup plus faible avec la LX qu'avec la $\mathrm{L}(2,4 \pm 2,1$ par rapport à $3,2 \pm 2,8$, respectivement $[-0,80 ; 95 \% \mathrm{IC}-1,54$ à $-0,06])$. Par rapport à la L, l'utilisation de la LX s'associait à une période beaucoup plus courte pour appliquer l'anesthésie $(2,4 \pm 1,8 \mathrm{~min}$ par rapport à $3,5 \pm 2,2 \mathrm{~min}$, respectivement $[-1,10 ; 95 \% \mathrm{IC}-1,71 \mathrm{~min}$ à $-0,50 \mathrm{~min}])$ et à une période d'insertion moins longue $(3,2 \pm 1,8 \mathrm{~min}$ par rapport à $3,9 \pm 2,2 \mathrm{~min}$, respectivement $[-0,70 \mathrm{~min} ; 95 \% \mathrm{IC}-1,30 \mathrm{~min}$ à $-0,10 \mathrm{~min}])$. L'épistaxis était rare, mais moins fréquente avec la LX $(1,1 \%)$ qu'avec la L $(4,6 \%)$ $(\mathrm{P}=0,19)$.

CONCLUSIONS : La LX n'améliorait pas le confort des patients pendant l'endoscopie transnasale par rapport à la $\mathrm{L}$ seule. Cependant, la LX s'associait à une diminution de la difficulté d'insérer l'endoscope par voie transnasale et réduisait la période d'insertion. D'autres études sur le régime posologique optimal et la dose d'anesthésie s'imposent.

\footnotetext{
${ }^{1}$ Division of Gastroenterology, University of Alberta; ${ }^{2}$ Royal Alexandra Hospital, University of Alberta Hospital, Edmonton, Alberta;

${ }^{3}$ Stanton Territorial Hospital, Yellowknife, Northwest Territories; ${ }^{4}$ Misericordia Hospital, Edmonton, Alberta

Correspondence: Dr Justin Cheung, Divsion of Gastroenterology, University of Alberta, Zeidler Ledcor Centre, 130 University Campus,

Edmonton, Alberta T6G 2X8. Telephone 780-492-8243, fax 780-492-1455, e-mail justin.cheung@ualberta.ca

Received for publication May 25, 2009. Accepted July 9, 2009
} 
$U_{\mathrm{f}}^{\mathrm{n}}$ nsedated transnasal endoscopy is an emerging option for esophagogastroduodenal endoscopy (1-3). The technique involves the application of topical nasal anesthesia and the insertion of a thin endoscope through the nasal cavity to gain access to the gastrointestinal tract. Transnasal gastroscope diameters have ranged from $5.3 \mathrm{~mm}$ to $6.0 \mathrm{~mm}$, compared with standard adult gastroscopes, with diameters of $9.0 \mathrm{~mm}$ to $9.4 \mathrm{~mm}$ (4-7). The potential advantages of using thinner endoscopes for transnasal endoscopy include decreased discomfort levels and the avoidance of sedation, thus making the procedure more cost-effective and time efficient (7-9).

A few studies $(4-6,8,9)$ have reported favourable patient tolerance for transnasal endoscopy. However, smaller endoscope diameters may make the procedure even more tolerable; a recently developed $4.9 \mathrm{~mm}$ endoscope is currently available (10). Another potential factor leading to procedural discomfort is the topical anesthesia administered. The two main categories of agents used are anesthetics (eg, lidocaine [L]) and vasocontrictors/decongestants (eg, xylometazoline [X], naphazoline, cocaine or adrenaline). Vasoconstrictors and decongestants potentially improve nasal cavity patency and reduce epistaxis. However, there is wide variability in the regimens used, ranging from no medications to either anesthetics or decongestants, or combinations of both $(1,4-6,8,10,11)$. Small, limited studies in transnasal laryngoscopy have compared different forms of decongestive agents $(12,13)$. There are no randomized trials that have evaluated the benefit of adding a decongestant agent to an anesthetic agent for transnasal upper gastrointestinal endoscopy. Therefore, the objective of the present study was to compare the effectiveness of $\mathrm{L}$ alone versus L plus X (LX) for topical anesthesia in unsedated ultrathin $4.9 \mathrm{~mm}$ transnasal endoscopy.

\section{METHODS}

\section{Patients}

During February 2008, subjects volunteering for the Aklavik Helicobacter pylori Project (14) at the Susie Husky Health Centre in Aklavik (Northwest Territories) were considered for enrollment. After explanation of the study protocol, a total of 200 patients were screened for eligibility. Inclusion criteria were any of the following: 18 years of age or older and able to provide informed consent, or nine to 17 years of age with informed consent of a parent or guardian. Patients with any of the following were excluded: refused transnasal endoscopy, refused unsedated endoscopy, presence of ischemic heart disease, uncontrolled hypertension, or an allergy or intolerance to $\mathrm{L}$.

\section{Topical anesthesia regimens}

Patients were randomly assigned to preprocedure topical anesthesia with L or LX applied by a trained transnasal endoscopy nurse. Patients were asked to indicate which of their nostrils was most patent. If neither was more patent, the right nostril was chosen by default. The topical $\mathrm{L}$ regimen consisted of $4 \% \mathrm{~L}$ solution $(5 \mathrm{~mL})$ that was sniffed then gargled $(5 \mathrm{~mL})$, given by a syringe separately. Patients sniffed the L solution while compressing the opposite nostril and tilting their head back. The sniff was monitored by the transnasal endoscopy nurse to ensure uniform application of the $\mathrm{L}$ to the posterior nasal cavity. This regimen was found to be effective by the investigators in a pilot study (15). The LX regimen consisted of a 3:1 mixture of $4 \% \mathrm{~L}$ solution and
$0.1 \%$ X (Otrivin, Novartis Canada) (three sprays to the nostril while sniffing and one spray to the posterior oropharynx). A spray technique was chosen for the regimen because $\mathrm{X}$ was provided and routinely used with a spray device. A physician, blinded to the topical anesthesia regimen, lubricated the nasal passage before endoscopy by slowly inserting a cotton-tipped applicator lubricated with $2 \% \mathrm{~L}$ gel $(2 \mathrm{~mL}$ to $5 \mathrm{~mL})$ until reaching the wall of the posterior nasal cavity.

\section{Endoscopy}

Transnasal endoscopy was performed by seven physicians skilled in transoral gastroscopy (all having performed more than 1000 endoscopy procedures), who had recently participated in a hands-on transnasal endoscopy training session (15). The physicians were blinded to the anesthesia regimen. Subjects underwent unsedated transnasal upper gastrointestinal endoscopy to the descending duodenum using an Olympus GIF-N180 endoscope (Olympus, Japan). The instrument is a $4.9 \mathrm{~mm}$ diameter endoscope with a working length of $110 \mathrm{~cm}$, a $2.0 \mathrm{~mm}$ single-instrument channel and a single vertical control dial. Before removal of the endoscope, five separate gastric biopsies were taken for histopathology and two for $\mathrm{H}$ pylori microbiology culture as part of the protocol for the Aklavik H pylori Project (14).

\section{Outcomes}

Overall patient discomfort was evaluated by a questionnaire on a validated 10 -point visual analogue scale $(1=$ no discomfort, $10=$ severe discomfort $)$ administered after recovery $(4,6,15,16)$. Patient tolerance including anxiety, pain, gagging and preference of endoscopy technique were also assessed. Physicians were surveyed regarding perceived patient discomfort and technical aspects during endoscopy such as nasal insertion difficulty, duodenal insertion difficulty, image quality and handling on a 10 -point scale ( 1 = excellent, 10 = very poor $)$, as previously described (17). Patient encounter times were also recorded in predefined intervals from the time of anesthesia initiation to the time of discharge. Other outcomes included completion rates and adverse events.

\section{Ethics}

The Aklavik $H$ pylori Project was reviewed and approved by the University of Alberta Health Research Ethics Board (Edmonton, Alberta), the Aurora College Institute (Northwest Territories) and Aklavik council members. Informed written consent was obtained from each participant or guardian.

\section{Statistical methods}

Analyses were performed using STATA/IC 10 statistical software (StataCorp, USA). The values of continuous variables were summarized as mean \pm SD, difference in means and 95\% CI. For two-tailed P values, the Student's $t$ test was used for continuous variables and the Fisher's exact test for dichotomous variables. Statistical significance was set at $\mathrm{P}<0.05$.

\section{RESULTS}

Nineteen of the 200 individuals evaluated were excluded due to refusal of transnasal endoscopy $(n=15)$ and request for sedation $(n=4)$ (Figure 1$)$. A total of 181 patients were randomly assigned to receive either $\mathrm{L}(\mathrm{n}=87)$ or LX $(\mathrm{n}=94)$. The mean age of the $\mathrm{L}$ group was 41 years (range 12 to 80 years) 


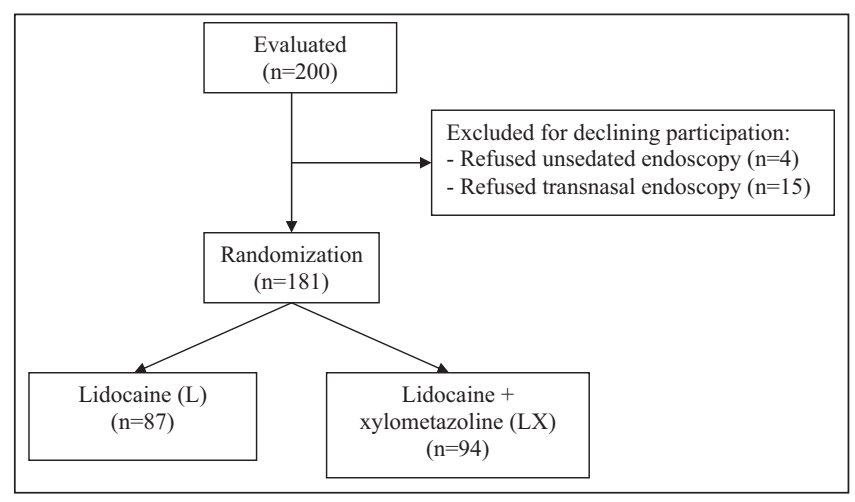

Figure 1) Study subject allocation

and 39 years (range 11 to 78 years) for the LX group. Baseline characteristics were similar in the two groups (Table 1).

\section{Patient rating}

There was no significant difference in the mean overall discomfort score rated by patients in the LX and $\mathrm{L}$ groups $(4.2 \pm 2.4$ versus $3.9 \pm 2.1$, respectively $[0.29 ; 95 \% \mathrm{CI}-0.39$ to 0.96]). No significant differences were found between the groups for other outcomes of tolerance such as anxiety, pain or gagging (Table 2). The highest level of pain was during initial insertion of the endoscope $(3.3 \pm 0.2)$ compared with the remainder of the procedure $(2.3 \pm 1.8)$.

\section{Physician rating}

There was no difference in the mean physician-rated patient discomfort comparing L and LX $(2.9 \pm 1.6$ versus $2.9 \pm 1.5$, respectively $[0.0 ; 95 \% \mathrm{CI}-0.47$ to 0.45$]$ ) (Table 3 ). The mean nasal endoscopy insertion difficulty score was significantly lower with LX compared with L $(2.4 \pm 2.1$ versus $3.2 \pm 2.8$, respectively $[-0.80 ; 95 \% \mathrm{CI}-1.54$ to -0.06$])$. A minimal difference in duodenal insertion difficulty was demonstrated (Table 3). Image quality and handling of the endoscope were rated favourably by both treatment groups.

\section{Encounter time}

The mean overall encounter time for unsedated transnasal endoscopy was lower with LX than with L $(21.4 \pm 6.0$ min versus $24.3 \pm 5.8 \mathrm{~min}$, respectively $(-2.9 \mathrm{~min} ; 95 \% \mathrm{CI}-4.64 \mathrm{~min}$ to $-1.09 \mathrm{~min}$ ) (Table 4$)$. The time for nasal anesthesia application was significantly lower with LX than with $\mathrm{L}(2.4 \pm 1.8 \mathrm{~min}$ versus $3.5 \pm 2.2 \mathrm{~min}$, respectively $[-1.10 \mathrm{~min} ; 95 \% \mathrm{CI}-1.71$ to $-0.50])$. The insertion time to the duodenum was significantly lower with LX than with $\mathrm{L}(3.2 \pm 1.8$ min versus $3.9 \pm 2.2 \mathrm{~min}$, respectively [ $-0.70 \mathrm{~min} ; 95 \% \mathrm{CI}-1.30$ to -0.10$]$ ). Similar times were found for the remaining encounter intervals (Table 4).

\section{Conversion/incomplete endoscopy}

Conversion to unsedated transoral endoscopy with the same endoscope occurred for eight patients (9.2\%) with LX and for $11(11.7 \%)$ patients with $\mathrm{L}(\mathrm{P}=0.63)$. Patients with a history of nasal fractures accounted for three of these 19 patients (LX: $\mathrm{n}=2, \mathrm{~L}: \mathrm{n}=1$ ). Conversion to sedated transoral endoscopy occurred for two patients in the L group (2.3\%, patient request). There was only one procedure in which the endoscope was unable to be inserted past the duodenal bulb.
TABLE 1

Patient characteristics

\begin{tabular}{lccc}
\hline & $\mathbf{L X}(\mathbf{n}=\mathbf{9 4})$ & $\mathbf{L}(\mathbf{n}=\mathbf{8 7})$ & $\mathbf{P}$ \\
\hline Age, years $($ mean $\pm \mathrm{SD})$ & $39 \pm 17.4$ & $41.0 \pm 16.7$ & 0.51 \\
Age $<18$ years & $12(13)$ & $8(9)$ & 0.49 \\
Female sex & $57(61)$ & $49(56)$ & 0.55 \\
Previous gastroscopy & $15(16)$ & $16(18)$ & 0.69 \\
\hline
\end{tabular}

Data presented as $n(\%)$ unless indicated otherwise. L Lidocaine; LX Lidocaine plus xylometazoline

\section{Endoscopy preference}

Among patients who completed transnasal endoscopy, 73\% $(n=62)$ in group LX and $73 \%(n=55)$ in group L would have preferred the identical unsedated transnasal technique if they were to require upper endoscopy in the future. Among patients who completed transnasal endoscopy and had previous experience with sedated transoral gastroscopy, $85 \%$ (23 of 27) preferred the unsedated transnasal technique.

\section{Side effects}

Epistaxis occurred more frequently with L than with LX (4.6\% versus $1.1 \%$, respectively; $\mathrm{P}=0.19$ ); however, there were too few events to adequately draw statistically based conclusions. All cases of epistaxis were mild and self-limited, or resolved with nasal compression only. Overall, there were more side effects associated with L $(14.9 \%, \mathrm{n}=13)$ than with LX $(8.5 \%$, $\mathrm{n}=8)(\mathrm{P}=0.19)$ but, again, the number of events was too small to be conclusive. Side effects associated with $\mathrm{L}$ included dysphagia $(\mathrm{n}=2)$, dizziness $(\mathrm{n}=2)$, nausea $(\mathrm{n}=2)$, bloating $(\mathrm{n}=1)$, upset stomach $(n=1)$ and vomiting $(n=1)$. Side effects with LX included dizziness $(n=1)$, nausea $(n=2)$, bloating $(n=1)$, sore throat $(n=1)$, tender nose $(n=1)$ and vomiting $(n=1)$.

\section{DISCUSSION}

Transnasal endoscopy is an emerging tool for the evaluation of the upper gastrointestinal tract. Comfort for the patient is important during transnasal endoscopy; however, there are limited data regarding the optimal regimen and technique for reducing discomfort $(11,16,18)$. The $\mathrm{L}$ only regimen used in the present study was found to be effective in achieving a reasonable level of comfort in a recent pilot study carried out by the current investigators (15). The current study showed that ultrathin transnasal endoscopy with topical LX did not improve patient comfort compared with L alone; however, LX was associated with less nasal insertion difficulty and reduced procedure time.

Overall discomfort and pain scores were similar between both anesthesia regimens. Patients tolerated ultrathin transnasal endoscopy well with either anesthesia regimen, resulting in a high completion rate (90\%). This is consistent with several reports showing high tolerability and completion rates for transnasal endoscopy $(3,6,10)$. The levels of pain experienced throughout the procedure were low for both treatment groups. There was only a minor difference in the mean discomfort level. However, the 0.30 score difference was not statistically significant and likely not clinically significant based on the 10-point scale used in the study. The low overall discomfort levels observed with both regimens may have been due to the use of the thinnest gastroscope currently available ( $4.9 \mathrm{~mm}$ diameter), compared with previous studies that used larger diameter endoscopes $(5.3 \mathrm{~mm}$ to $6.0 \mathrm{~mm})(4-6,8)$. A recent study with the same $4.9 \mathrm{~mm}$ endoscope (10) showed that patients experience 
TABLE 2

Patient postendoscopy survey

\begin{tabular}{|c|c|c|c|c|}
\hline \multirow[b]{2}{*}{ Question } & \multicolumn{2}{|c|}{ Score* } & \multirow[b]{2}{*}{$\begin{array}{c}\text { Difference in mean } \\
\text { score }(95 \% \mathrm{Cl})\end{array}$} & \multirow[b]{2}{*}{$\mathbf{P}$} \\
\hline & $\begin{array}{c}\text { Lidocaine + } \\
\text { xylometazoline }\end{array}$ & Lidocaine & & \\
\hline What was your level of overall discomfort during the procedure? & $4.2 \pm 2.4$ & $3.9 \pm 2.1$ & $0.29(-0.39$ to 0.96$)$ & 0.40 \\
\hline What was your anxiety level before we started the freezing procedure? & $3.9 \pm 2.8$ & $3.6 \pm 2.7$ & $0.29(-0.52$ to 1.11$)$ & 0.48 \\
\hline What was your pain level in your nose during the freezing with the medicine liquid? & $1.8 \pm 1.9$ & $1.7 \pm 2.1$ & $0.05(-0.48$ to 0.58$)$ & 0.86 \\
\hline What was your pain level in your nose during the initial insertion of the scope into the nose? & $3.2 \pm 0.2$ & $3.4 \pm 0.2$ & $-0.18(-0.78$ to 0.41$)$ & 0.54 \\
\hline What was your pain level in your nose during the remainder of the scope procedure? & $2.3 \pm 1.8$ & $2.2 \pm 1.8$ & $0.14(-0.39$ to 0.67$)$ & 0.60 \\
\hline What was your level of gagging during the procedure? & $2.4 \pm 2.2$ & $2.1 \pm 1.6$ & $0.35(-0.17$ to 0.86$)$ & 0.18 \\
\hline
\end{tabular}

Data presented as mean $\pm S D$ unless indicated otherwise. ${ }^{*}$ Discomfort visual analogue scale: $1-10(1=$ none, $5=$ moderate, $10=$ severe)

TABLE 3

Endoscopist postendoscopy survey

\begin{tabular}{|c|c|c|c|c|}
\hline \multirow[b]{2}{*}{ Question } & \multicolumn{2}{|c|}{ Score } & \multirow[b]{2}{*}{$\begin{array}{c}\text { Difference in mean } \\
\text { score }(95 \% \mathrm{Cl})\end{array}$} & \multirow[b]{2}{*}{$\mathbf{P}$} \\
\hline & $\begin{array}{c}\text { Lidocaine + } \\
\text { xylometazoline }\end{array}$ & Lidocaine & & \\
\hline What was the level of overall discomfort experienced by the patient?* & $2.9 \pm 1.5$ & $2.9 \pm 1.6$ & $0.0(-0.47$ to 0.45$)$ & 0.97 \\
\hline What was the level of difficulty with transnasal insertion ${ }^{\dagger}{ }^{\dagger}$ & $2.4 \pm 2.1$ & $3.2 \pm 2.8$ & $-0.80(-1.54$ to -0.06$)$ & 0.03 \\
\hline What was the level of difficulty with performing endoscopy down to 2 nd duodenum ${ }^{\dagger}$ & $1.9 \pm 1.2$ & $2.1 \pm 1.5$ & $-0.21(-0.62$ to 0.19$)$ & 0.30 \\
\hline What was the level of image quality (ie, clarity, resolution) ${ }^{\dagger}$ & $2.1 \pm 1.0$ & $2.1 \pm 1.3$ & $0.0(-0.33$ to 0.33$)$ & 0.98 \\
\hline What was the level of handling of the scope (ie, manoeuverability)? ${ }^{\dagger}$ & $2.2 \pm 1.2$ & $2.3 \pm 0.8$ & $0.10(-0.42$ to 0.22$)$ & 0.53 \\
\hline
\end{tabular}

Data presented as mean $\pm S D$ unless indicated otherwise. ${ }^{*}$ Discomfort visual analogue scale: $1-10\left(1=\right.$ none, $5=$ moderate, $10=$ severe); ${ }^{\dagger}$ Technical visual analogue scale: $1-10(1=$ excellent, $5=$ moderate, $10=$ very poor $)$

TABLE 4

Patient encounter times

\begin{tabular}{|c|c|c|c|c|}
\hline \multirow[b]{2}{*}{ Interval } & \multicolumn{2}{|c|}{ Time, min } & \multirow[b]{2}{*}{$\begin{array}{c}\text { Difference in mean } \\
\text { time }(95 \% \mathrm{Cl})\end{array}$} & \multirow[b]{2}{*}{$\mathbf{P}$} \\
\hline & $\begin{array}{c}\text { Lidocaine + } \\
\text { xylometazoline }\end{array}$ & Lidocaine & & \\
\hline Nasal freezing & $2.4 \pm 1.8$ & $3.5 \pm 2.2$ & $-1.10(-1.71$ to -0.50$)$ & $<0.001$ \\
\hline Postfreezing to nasal insertion & $5.8 \pm 3.0$ & $6.4 \pm 3.5$ & $-0.55(-1.53$ to 0.43$)$ & 0.23 \\
\hline Nasal insertion down to duodenum & $3.2 \pm 1.8$ & $3.9 \pm 2.2$ & $-0.70(-1.30$ to 0.10$)$ & 0.02 \\
\hline Duodenal insertion to scope removal ${ }^{*}$ & $6.3 \pm 2.5$ & $6.5 \pm 2.2$ & $-0.22(-0.92$ to 0.49$)$ & 0.54 \\
\hline Scope removal to leaving room & $2.7 \pm 2.1$ & $2.8 \pm 1.7$ & $-0.09(-0.67$ to 0.49$)$ & 0.45 \\
\hline Leaving room to discharge & $1.0 \pm 1.6$ & $1.3 \pm 2.0$ & $-0.21(-0.75$ to 0.33$)$ & 0.45 \\
\hline Total encounter time & $21.4 \pm 6.0$ & $24.3 \pm 5.8$ & $-2.9(-4.64$ to -1.09$)$ & 0.002 \\
\hline
\end{tabular}

Data presented as mean \pm SD unless indicated otherwise. ${ }^{*}$ Time interval included a protocol for seven separate gastric biopsies

less discomfort with smaller diameter endoscopes. The discomfort and pain levels reported with both anesthesia regimens did not appear to be a clinically significant deterrent, because $73 \%$ of patients in both treatment groups would have preferred the unsedated transnasal technique if a future endoscopy was required.

Topical X may theoretically reduce epistaxis because of its nasal vasoconstrictive and decongestant action. There were fewer episodes of epistaxis with LX in the present trial, but epistaxis frequency was low, even in patients receiving $\mathrm{L}$ only (less than $5 \%$ ) (6,7). This may be due to the benefits of the thinner $4.9 \mathrm{~mm}$ transnasal endoscope (10). However, the study was not powered for a statistically precise comparison, given the low rate of epistaxis.

In terms of technical factors, less time was required for anesthesia application and transnasal endoscope insertion with the LX regimen. Endoscopists also reported less difficulty with transnasal insertion with the combination regimen. The reduced time and difficulty with transnasal insertion may be supportive evidence that the vasoconstrictive and decongestive properties of $\mathrm{X}$ produce a more patent and easier passageway through the nasal cavity. The mean time for transnasal insertion down to the duodenum was reduced with the LX regimen. Insertion time with either treatment group was less than 4 min and is consistent with insertion times reported in other transnasal endoscopy studies $(5,10)$. Overall, LX nasal spray reduced the mean total patient encounter time by approximately $3 \mathrm{~min}$. Finally, although a thinner transnasal endoscope may potentially compromise handling and image quality, especially in the nasal cavity, endoscopists found excellent handling and image quality regardless of the treatment group.

A potential limitation of the present study is that the reduced difficulty with nasal insertion and reduced procedure times with LX could be due to a more effective mode of medication delivery (spray versus solution) rather than actual medication effects. However, this effect is unlikely given that pain scores were similar in both treatments, indicating that the overall effect of anesthesia was similar. In addition, the optimal dose of LX is unknown. Perhaps a higher dose of $\mathrm{X}$ than that used in the present study may have been more efficacious.

Although there are certain centres in Canada that routinely use unsedated transnasal endoscopy, it is currently not 
universally accepted, especially in North America, for the evaluation of the upper gastrointestinal tract (1). Barriers to the use of transnasal endoscopy in North America may include patient expectation for sedation, endoscope cost, unfamiliarity with the equipment and nasal anatomy. However, unsedated transnasal upper endoscopy is routine in many centres in Asia and Europe $(8,10,17,18)$.

\section{CONCLUSION}

LX did not appear to improve comfort for unsedated $4.9 \mathrm{~mm}$ ultrathin transnasal endoscopy compared with $\mathrm{L}$ alone. However, LX was associated with reduced insertion and procedure time, and endoscopists had less difficulty with transnasal insertion. Further studies evaluating the optimal regimen and dosing for topical anesthesia are required.

AUTHOR CONTRIBUTIONS: All coauthors fundamentally contributed to the design, data collection, interpretation and writing of the manuscript. All authors have read and approved the paper.

ACKNOWLEDGEMENT: The authors acknowledge the contributions of Olympus Canada personnel Peter Bresee and Dale Kennedy, University of Alberta Hospital patient care manager Susan Derk, Royal Alexandra Hospital endoscopy program manager Brenda Holowaty, University of Alberta Hospital and Royal Alexandra Hospital (Edmonton, Alberta) endoscopy nurses Leanne Ellis, Jennifer Antonio, Sheila Berrisford, Kathy Korner, Cinnamon Landhauser, Paula Ledsham, Louise Steffan, and service aids Austin Babb, Tamara Bangs, Tammy Church and Sharda Naidu and Inuvik Regional Hospital endoscopy aid Louie Goose.

CANHelP WORKING GROUP: Aklavik, Northwest Territories (NWT): Rachel Munday (Aklavik Health Centre); Robert Buckle, Glen Gordon, Annie Buckle, Jerome Gordon, Andrew Gordon (Aklavik Health Committee); Billy Archie (Arctic Health Research Network). Inuvik, NWT: Leah Seaman (Inuvik Regional Hospital), Crystal Lennie (Inuvialuit Regional Corporation). Yellowknife, NWT: Andre Corriveau (NWT Health and Social Services), John Morse (Stanton Territorial Health Authority), Susan Chatwood (Arctic Health Research Network). Edmonton, Alberta: Karen Goodman, Justin Cheung, Michael Arget, Richard Fedorak, Christopher Fletcher, Safwat Girgis, Janis Huntington, Monika Keelan, Carl Phillips, Robert Rennie, Larissa Shamseer, Joanne Simala-Grant, Sander Veldhuyzen van Zanten (University of Alberta); Robert Bailey (Capital Health Northern Health Services Network).

CONFLICTS OF INTEREST: The authors have no financial disclosures or conflicts of interest. Olympus Canada loaned and delivered endoscopic equipment with technical support, but had no involvement in the study design, data collection, data analysis or manuscript composition.

FINANCIAL SUPPORT: Dr Justin Cheung is a clinical research fellow supported by fellowships from the Canadian Association of Gastroenterology, the Canadian Institutes of Health Research, Ferring Pharmaceuticals and the Alberta Heritage Foundation for Medical Research. The activities of the Aklavik H pylori Project to date have been supported by funds from the Social Sciences and Humanities Research Council of Canada, the University of
Alberta Division of Gastroenterology, the Northwest Territories Health and Social Services, and the Inuvialuit Regional Corporation, along with in-kind contributions from Olympus Canada, Canadian North Airlines, Capital Health, Inuvik Regional Hospital, Susie Husky Health Centre, Aklavik Community Corporation, and Aklavik residents and community groups who housed and fed endoscopy team members.

\section{REFERENCES}

1. Cho S, Arya N, Swan K, et al. Unsedated transnasal endoscopy: A Canadian experience in daily practice. Can J Gastroenterol 2008;22:243-6.

2. Dumortier J, Napoleon B, Hedelius F, et al. Unsedated transnasal EGD in daily practice: Results with 1100 consecutive patients. Gastrointest Endosc 2003;57:198-204.

3. Postma GN, Cohen JT, Belafsky PC, et al. Transnasal esophagoscopy: Revisited (over 700 consecutive cases). Laryngoscope 2005;115:321-3.

4. Preiss C, Charton JP, Schumacher B, Neuhaus H. A randomized trial of unsedated transnasal small-caliber esophagogastroduodenoscopy (EGD) versus peroral small-caliber EGD versus conventional EGD. Endoscopy 2003;35:641-6.

5. Trevisani L, Cifala V, Sartori S, Gilli G, Matarese G, Abbasciano V. Unsedated ultrathin upper endoscopy is better than conventional endoscopy in routine outpatient gastroenterology practice: A randomized trial. World J Gastroenterol 2007;13:906-11.

6. Murata A, Akahoshi K, Sumida Y, Yamamoto H, Nakamura K, Nawata $\mathrm{H}$. Prospective randomized trial of transnasal versus peroral endoscopy using an ultrathin videoendoscope in unsedated patients. J Gastroenterol Hepatol 2007;22:482-5.

7. Bampton PA, Reid DP, Johnson RD, Fitch RJ, Dent J. A comparison of transnasal and transoral oesophagogastroduodenoscopy. J Gastroenterol Hepatol 1998;13:579-84.

8. Yagi J, Adachi K, Arima N, et al. A prospective randomized comparative study on the safety and tolerability of transnasal esophagogastroduodenoscopy. Endoscopy 2005;37:1226-31.

9. Campo R, Montserrat A, Brullet E. Transnasal gastroscopy compared to conventional gastroscopy: A randomized study of feasibility, safety, and tolerance. Endoscopy 1998;30:448-52.

10. Dumortier J, Josso C, Roman S, et al. Prospective evaluation of a new ultrathin one-plane bending videoendoscope for transnasal EGD: A comparative study on performance and tolerance. Gastrointest Endosc 2007;66:13-9.

11. Lee YC, Wang CP. Cotton Pledget method for nasal decongestive anesthesia prior to transnasal endoscopy. Am J Gastroenterol 2008 [Epub ahead of print].

12. Smith JC, Rockley TJ. A comparison of cocaine and 'co-phenylcaine' local anaesthesia in flexible nasendoscopy. Clin Otolaryngol Allied Sci 2002;27:192-6.

13. Johnson PE, Belafsky PC, Postma GN. Topical nasal anesthesia for transnasal fiberoptic laryngoscopy: A prospective, double-blind, cross-over study. Otolaryngol Head Neck Surg 2003;128:452-4.

14. Cheung J, Goodman K, Munday R, et al. Helicobacter pylori infection in Canada's arctic: Searching for the solutions. Can J Gastroenterol 2008;22:912-6.

15. Cheung J, Bailey R, Veldhuyzen van Zanten S, et al. Early experience with unsedated ultrathin $4.9 \mathrm{~mm}$ transnasal gastroscopy: A pilot study. Can J Gastroenterol 2008;22:917-22.

16. Zaman A, Hahn M, Hapke R, Knigge K, Fennerty MB, Katon RM. A randomized trial of peroral versus transnasal unsedated endoscopy using an ultrathin videoendoscope. Gastrointest Endosc 1999;49:279-84

17. Birkner B, Fritz N, Schatke W, Hasford J. A prospective randomized comparison of unsedated ultrathin versus standard esophagogastroduodenoscopy in routine outpatient gastroenterology practice: Does it work better through the nose? Endoscopy 2003;35:647-51.

18. Hu CT. Endoscopic-guided versus cotton-tipped applicator methods of nasal anesthesia for transnasal esophagogastroduodenoscopy: A randomized, prospective, controlled study. Am J Gastroenterol 2008;103:1114-21. 


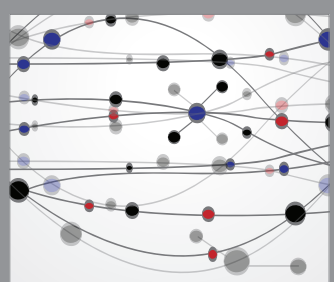

The Scientific World Journal
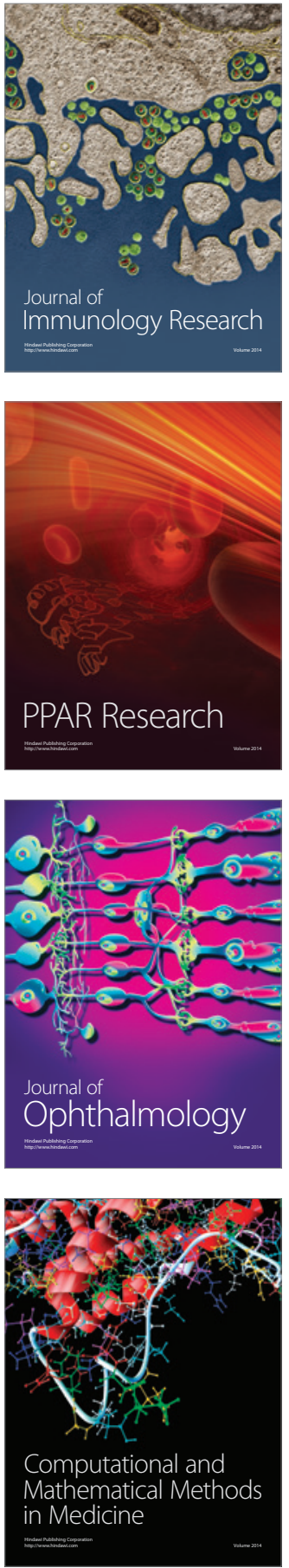

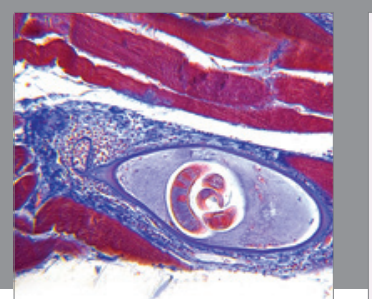

Gastroenterology Research and Practice

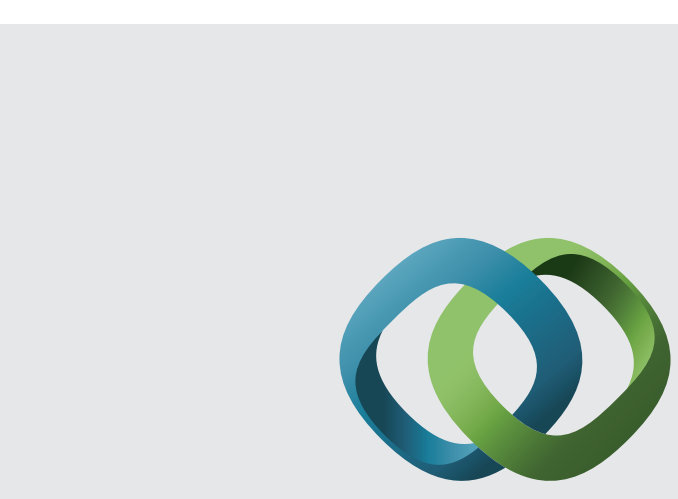

\section{Hindawi}

Submit your manuscripts at

http://www.hindawi.com
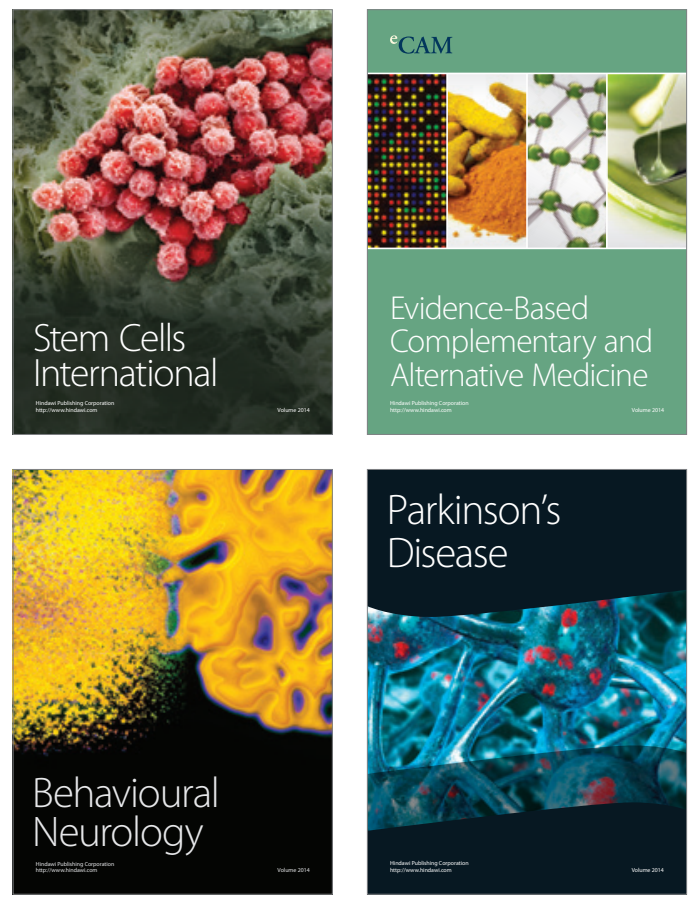
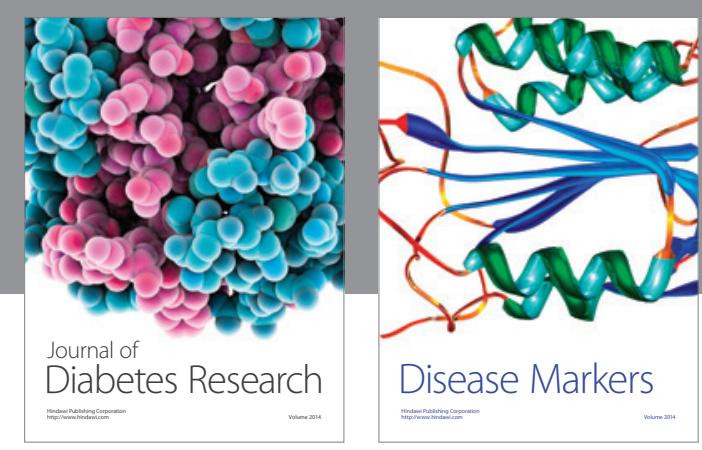

Disease Markers
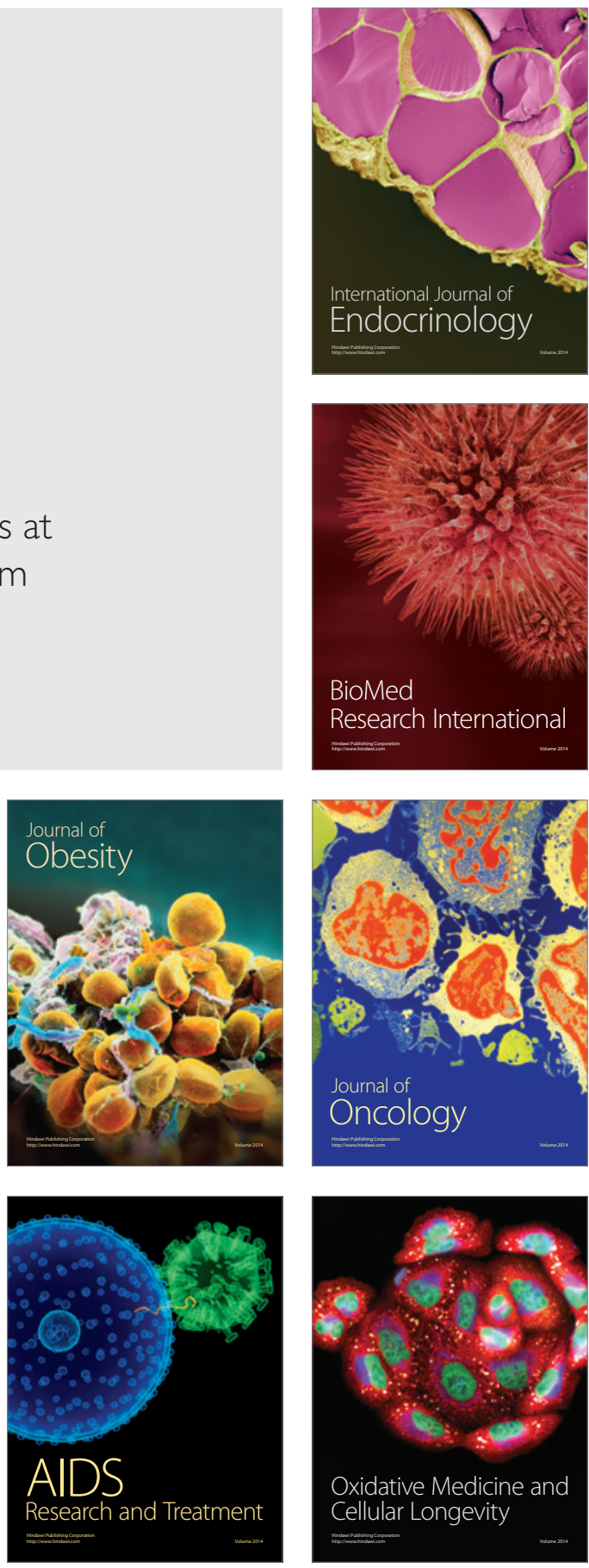